\title{
Regulation of nutrient intake in nectar-feeding birds: insights from the geometric framework
}

Angela Köhler ${ }^{1}$, David Raubenheimer ${ }^{2,3}$ and Susan W. Nicolson ${ }^{1 *}$

${ }^{1}$ Department of Zoology \& Entomology, University of Pretoria, South Africa

${ }^{2}$ Institute of Natural Sciences, Massey University, Albany, New Zealand

${ }^{3}$ National Research Centre for Growth and Development, New Zealand

*Corresponding author: swnicolson@zoology.up.ac.za 


\begin{abstract}
A nectar diet is simple in composition and easily digested, but may vary greatly in its proportions of sugar and water. Here we apply the geometric framework, a modelling approach for investigating how animals balance nutrient needs in multidimensional and dynamic nutritional environments, to captive whitebellied sunbirds (Cinnyris talatala). We address the question of how these small birds $(\sim 8 \mathrm{~g})$ prioritize sugar and water intake, and how dietary salt content interacts with sugar and water intake. Sunbirds kept at $20^{\circ} \mathrm{C}$ and provided with moderate to high sucrose concentrations $(\geq 1 \mathrm{M})$, together with supplementary water, converge on an intake target of $2.79 \mathrm{~g} \mathrm{day}^{-1}$ of sucrose and $7.72 \mathrm{~g} \mathrm{day}^{-1}$ of water: equivalent to $0.85 \mathrm{M}$ sucrose. When the birds are given more dilute sucrose concentrations, they defend their sugar intake by overingesting water, up to a ceiling of $47 \mathrm{~g} \mathrm{day}^{-1}$. Sugar intake thus gets priority over water intake, but the birds have a finite capacity to over-ingest water to gain the target level of sugar. Regulation appears to be less precise when birds are given a choice between two sucrose solutions than when they choose between a sugar solution and supplementary water. Intake targets vary in response to internal and external factors, and sunbirds increase their sugar intake in response to increased activity and cold, irrespective of nectar concentration. They also compensate for interruptions in foraging activity, whether overnight or during the day. Interactive effects became evident when sodium was included as a third nutrient: on very dilute nectar $(\leq 0.1 \mathrm{M})$, where sunbirds lose body mass, the addition of sodium to the diet helps to achieve the carbohydrate intake target, while raising the ceiling on water intake. This analysis provides a new perspective on nectarivory, while adding to the comparative database on nutrient regulation and emphasising water as a nutrient.
\end{abstract}

Key-words: whitebellied sunbird, Cinnyris talatala, sucrose, sodium, water, intake target, rule of compromise 


\section{Introduction}

There is a growing awareness that nutrition is best understood in a multidimensional context, where foraging is viewed as a dynamic process of balancing the intake and utilization of multiple nutrients to satisfy complex and dynamic nutrient needs. The Geometric Framework for Nutrition (GF) is a modelling approach for exploring how an animal simultaneously regulates the intake of multiple nutrients (Raubenheimer and Simpson 1993,1999; Simpson and Raubenheimer 1993,1995). A distinctive aspect of GF is that it provides multidimensional measures of key aspects of nutritional regulation, including nutrient requirements (the "nutritional targets") and the ways that animals resolve the tradeoff between over-ingesting some nutrients and under-ingesting others when feeding on nutritionally imbalanced foods (the "rule of compromise"). Such measures provide a common basis for comparing the nutritional strategies of diverse animals (Raubenheimer and Simpson 1997; Simpson and Raubenheimer 1993).

GF has been applied in a wide range of systems, spanning unicellular slime moulds (Dussutour et al. 2010) to metazoans, insects to humans (Gosby et al. 2011; Simpson et al. 2003), solitary to eusocial animals (Altaye et al. 2010; Dussutour and Simpson 2009), herbivores, omnivores and carnivores (Mayntz et al. 2005; Raubenheimer et al. 2007), invertebrates and vertebrates (Raubenheimer and Simpson 1997), terrestrial and marine organisms (Raubenheimer et al. 2005), and both in laboratory and field studies (Felton et al. 2009; Rothman et al. 2011). This broad comparative perspective has yielded novel insights into a range of issues, including differences in the patterns of nutrient regulation between generalist and specialist feeders, and among feeding guilds; relationships between nutrition, reproduction and lifespan, and between nutrition and immune responses; the nutritional basis for niche divergence among sympatric species, and the causes of human obesity (Simpson and Raubenheimer 2005).

Among the under-represented groups in the comparative study of multidimensional nutrition are birds, which to date have been the focus of only three such studies of which we are aware. Raubenheimer and Simpson (1997) re-analysed the data of Shariatmadari and Forbes (1993) to show that broiler chickens adjust their intakes of different food pairings to defend a two-dimensional target intake of carbohydrate and protein. Schaefer et al. (2003) studied the 
nutrient choices and discrimination abilities of four species of frugivorous tanagers, but did not show whether the birds defended intake targets. Raubenheimer and Simpson (2006) used nutritional geometry to compare the compositions of the natural breeding foods of the critically endangered New Zealand parrot, the kakapo, and supplementary feeds designed to increase the rate of reproduction. A second group that is under-represented in the geometric study of nutrition is nectar feeders. Raubenheimer (2011) recommended a three-dimensional graphical approach for comparing nectar compositions, and combined and re-plotted the data of Barnes et al. (1995) and Baker et al. (1998) to show how this approach might contribute to the comparative study of pollination syndromes. There exist no studies, however, in which the nutritional geometry has been used to characterise the regulatory dynamics of nectarivorous birds.

Consumption of a predominantly nectar diet poses interesting questions about nutrient regulation. Nectar is a simple food source consisting mainly of sugar and water, easily digested and rich in energy. In addition, nectar contains inorganic ions, amino acids, proteins, lipids and secondary metabolites in smaller quantities (Nicolson and Thornburg 2007). Nectar-feeding birds have high energy requirements due to their small body size and energetic lifestyles, and use recently ingested carbohydrates to fuel up to $95 \%$ of their metabolism (Welch and Suarez 2007). They are highly efficient in utilising sugar, with $>99 \%$ of ingested sugar being assimilated, even at maximal feeding rates (Köhler et al. 2010b). Nevertheless, they have to ingest copious amounts of characteristically dilute nectars in order to maintain energy balance, resulting in energetic and osmoregulatory challenges (Lotz et al. 2003; Nicolson and Fleming 2003b).

In previous studies, we have extensively examined the behaviour and physiology associated with nectar feeding in whitebellied sunbirds Cinnyris talatala (body mass 7-9 g). Here we apply the Geometric Framework to examine nutrient intake regulation in whitebellied sunbirds as a model species for avian nectarivores. We focus on the short-term regulation of sugar and water, and examine how a third nutrient, salt, interacts with this regulation. We use the Geometric Framework in an attempt to integrate previously published data concerning different aspects of nectar feeding and provide a better understanding of nutritional regulation in this species. 


\section{Target selection}

A fundamental step in geometric analysis is to establish whether the homeostatic systems involved in feeding have a regulatory target, or 'set point' (Raubenheimer and Simpson 1997; Simpson and Raubenheimer 1995). On the assumption that the regulatory priorities of animals have evolved through natural selection, nutritional regulatory set points can be considered 'intake targets', defined as the amount and balance of nutrients that supports maximal fitness. Several experiments involving invertebrates have shown a tight correspondence between nutritional regulatory set points and animal fitness (e.g. Behmer and Joern 2008; Lee et al. 2008; Raubenheimer and Simpson 1997; Simpson et al. 2004).

The basic protocol for testing whether animals have regulatory targets for specific nutrients is as follows (Simpson and Raubenheimer 1995). Experimental animals are provided with nutritionally unbalanced but complementary food combinations, thus enabling them to select a diet of the preferred composition. To ensure that the selected point really is a homeostatic target rather than, for example, the outcome of indiscriminate feeding on the available foods, different experimental groups of animals are given different combinations of foods that are complementary with respect to the nutrients of interest, and their nutrient intakes compared. If feeding is governed by non-homeostatic processes (e.g. equal intakes from each food), then nutrient intakes would passively follow the compositions of the respective food pairings and differ across experimental groups. On the other hand, if the experimental groups specifically spread their feeding across their respective food combinations so as to achieve the same nutrient gain, this demonstrates that the identified point is a homeostatically defended target.

Nicolson and Fleming (2003a) performed an experiment that tested for a regulatory target with respect to sucrose and water intake in sunbirds. Each bird was provided with access to one of seven concentrations of sucrose solutions ranging from 0.07 to $2.5 \mathrm{M}$. In Fig. 1, each of these solutions is represented by a different nutritional rail, where the angle of the rail is proportional to the sugar concentration. In addition to the respective sugar solutions, each bird was also provided with a source of supplementary water, and in this way was given an opportunity to 
balance its intake of sucrose and water over a day. In geometric terms, this design enabled each group of birds to compose a diet with composition that fell anywhere between the nutritional rail representing its sugar solution and the $\mathrm{x}$-axis (which represents the nutritional rail for water), but the birds could not achieve a diet that falls outside of this area.

As can be seen in Fig. 1, the composition of the diets of birds provided with sucrose solutions of concentrations $0.07 \mathrm{M}$ to $0.5 \mathrm{M}$ corresponded almost exactly with the compositions of their respective sucrose solutions, indicating that they had drunk little if any of the supplementary water. Intakes of the birds given more concentrated sugar solutions $(1 \mathrm{M}, 1.5 \mathrm{M}$, $2 \mathrm{M}$ or $2.5 \mathrm{M}$ ), by contrast, did not passively follow the compositions of their respective sucrose solutions, but all converged on a statistically indistinguishable point representing $7.72 \pm 0.81$ (mean $\pm \mathrm{SE}$ ) g day ${ }^{-1}$ of water and $2.79 \pm 0.04 \mathrm{~g} \mathrm{day}^{-1}$ of sucrose, giving a concentration of about $0.85 \mathrm{M}$ sucrose. To converge in this way, the birds on each of the more concentrated sucrose solutions $(1-2.5 \mathrm{M})$ had to combine in their diet supplementary water with their respective sugar solutions in different proportions, thus demonstrating that they homeostatically regulated the balance and amounts of sugar and water in their daily diet.

Although the birds on the more dilute sugar solutions $(0.07-0.5 \mathrm{M})$ did not converge on the target point, their response nonetheless provides clear evidence of regulation towards a target. These birds were constrained from reaching the target position, because in each case the concentration of the available sugar solution was lower than the target concentration of $0.85 \mathrm{M}$. Their only alternative food was supplementary water which if ingested would further dilute the diet. By avoiding this and almost exclusively ingesting the sugar solution they therefore selected the diet that was as close to the target concentration as was possible. This demonstrates that when prevented from reaching the target point sunbirds select a diet with a sugar concentration that is as close as possible, given available foods, to the $0.85 \mathrm{M}$ concentration of the target diet.

\section{When the target cannot be reached: the rule of compromise}

In addition to the intake target, a second important parameter of nutritional regulatory systems is how they respond when the compositions of available foods prevent the target from being 
reached. In the absence of an option to select alternative foods, the critical decision faced by animals in this predicament is how much of the imbalanced diet to eat. Although at surface value this is a simple question of diet quantity, underpinning this decision is an important set of tradeoffs that are exposed to scrutiny using geometric analysis.

Consider, for example, the sunbirds in Fig. 1. As discussed above, the birds on the more dilute sugar solutions $(0.07 \mathrm{M}, 0.1 \mathrm{M}, 0.25 \mathrm{M}$ and $0.5 \mathrm{M})$ could not access the area of nutrient space in which the intake target lies (c. $0.85 \mathrm{M}$ sucrose), but by rejecting the supplementary water and almost exclusively ingesting the sugar solution they nonetheless arrived at a point that fell approximately on the nutritional rail that was as close to the target as their respective food pairings permitted. But how much of this sugar solution should they ingest? At the one extreme, if the sunbirds regulated along their respective rails to a point that aligned horizontally with the intake target, this would minimize (in fact reduce to 0 ) the distance from the target with respect to the Y-coordinate (sucrose in Fig. 1), but in so doing the birds would ingest excess water. Another strategy would be to align with the target in terms of water (vertically), but this would result in a large deficit of sucrose. Alternatively, the animal could adopt an intermediate strategy in which it suffers a deficit of sucrose as well as a surplus of water, but neither of which are as large as in the first two strategies. The option adopted by animals in this circumstance is known as a "rule of compromise", because it reflects the compromise reached between over-ingesting some nutrients and under-ingesting others when feeding on nutritionally imbalanced diets (Raubenheimer and Simpson 1999). Rules of compromise are expected to reflect the cost-benefit structure of ingesting excesses and deficits of the nutrients involved (Simpson et al. 2004).

What do the data in Fig. 1 reveal about the rule of compromise for sunbirds when forced to tradeoff the intake of dietary sugar against water? The birds on sugar concentrations $0.5 \mathrm{M}$ and $0.25 \mathrm{M}$ had intakes that aligned on the $\mathrm{Y}$-axis with the target, showing that they defended their gain of sucrose and to do so over-ingested water. Those on the more dilute sugar solutions $(0.1$ and $0.07 \mathrm{M})$, by contrast, did not achieve the target value for either water or sucrose, but aligned with each other on the X-axis. Nutritionally, this indicates that the birds in these two treatments ingested the same amount of water $\left(47 \mathrm{~g} \mathrm{day}^{-1}\right)$, but their sugar intakes passively followed the sugar concentrations of their respective diets - i.e. $0.1 \mathrm{M}$ and $0.07 \mathrm{M}$. This strongly 
suggests that $47 \mathrm{~g}$ day $^{-1}$ represents a limit to water intake beyond which the birds will not go, regardless of whether this restricts their sugar intake to $1.62 \mathrm{~g} \mathrm{day}^{-1}$ (the $0.1 \mathrm{M}$ treatment) or 1.14 $\mathrm{g} \mathrm{day}^{-1}$ (the $0.07 \mathrm{M}$ treatment). Overall, the data thus suggest that sunbirds will over-ingest water to defend their sugar gain, but have a finite capacity to do so. As we shall see below, however, this is contingent on the concentration in the diet of another nutrient, salt.

A question that is not answered by the data in Fig. 1 is how sunbirds resolve the conflict between sugar and water when confined to sugar solutions that are more concentrated than the target concentration. The data of Leseigneur and Nicolson (2009) enable us to address this question. These authors provided sunbirds with different combinations of foods, as in the experiment presented in Fig. 1, but in this case each bird had access to two sugar solutions rather than a single sugar solution paired with supplementary water, with the treatment pairings consisting of consecutive solutions in a graded series ranging from $0.25 \mathrm{M}$ to $2.5 \mathrm{M}$ (Fig. 2). Consequently, each bird was confined to a restricted geometric area bounded by the two consecutive nutritional rails representing the foods in their respective treatment.

Figure 2 presents a geometric analysis of the data. A first point to note from the figure is that there is an asymmetry between intake points to the right and left of the nutritional rail representing $1 \mathrm{M}$ sucrose. Birds on food pairings that confined them to segments of nutrient space with lower sucrose concentrations (i.e. to the right of the plot) had intake points closer to the more concentrated food in their respective pairing (i.e. left rail), whereas those on more concentrated pairings had intakes closer to the more dilute option (i.e. right rail). This suggests that the regulatory systems are tending towards a position somewhere between the intake points for treatments 0.5 vs. $1 \mathrm{M}$ and 1 vs. $1.5 \mathrm{M}$, indicating that the intake target for this experiment is most likely in this region. This is consistent with the selected target of $0.85 \mathrm{M}$ in the data of Nicolson and Fleming (2003a) (Fig. 1).

A second point to note from this figure is that all intake points aligned on the sucrose axis, demonstrating that sunbirds prioritise sugar intake over water. This replicates the result for the experiment shown in Fig. 1, where sunbirds on dilute diet treatments (i.e. $0.25 \mathrm{M}$ and $0.5 \mathrm{M}$ sucrose) likewise aligned with the target on the sucrose axis. The new result from Fig. 2, 
however, is that these data show that when confined to diets with a higher sucrose concentration than the target diet (i.e. to the left of the target), sunbirds also aligned with the target on the sugar axis. These experiments thus show that within the range of concentrations tested by Leseigneur and Nicolson (2009), sunbirds respond to variation in the sugar:water balance of the diet by defending sugar gain, whether this involves over- or under-ingesting water.

A third interesting point is suggested by comparing the data in figures 1 and 2, namely that regulation of the sugar:water balance of the diet is apparently less precise when sunbirds mix their diet from two sugar solutions (Fig. 2) compared with one sugar solution vs. supplementary water (Fig. 1). In Fig. 1, all of the experimental groups that had access to the target (i.e. those given sugar solutions of concentration $1 \mathrm{M}$ or greater together with supplementary water) converged on an intake target, and those that could not reach the target regulated to the rail that was as close to the target rail as they could get given their respective treatment. By contrast, such precise regulation was not seen in Fig. 2. If we assume that the target concentration is $0.85 \mathrm{M}$ (as in Fig. 1), then the birds on treatment 1 vs. $1.5 \mathrm{M}$ would have optimised their diet by rejecting the $1.5 \mathrm{M}$ solution and feeding exclusively on the $1 \mathrm{M}$ solution. However, the fact that the mean intakes for these birds did not fall on the $1 \mathrm{M}$ rail, but rather between the 1 and $1.5 \mathrm{M}$ rails, shows that they mixed their intake from the two foods, even though this resulted in a diet with greater sucrose concentration than is optimal. Similarly, birds on the 1.5 vs. $2 \mathrm{M}$ treatment had mean intakes that fell between the food rails, rather than on the least concentrated rail as would be predicted if they were regulating optimally. It is possible, on the other hand, that the true target for the birds in this experiment is not $0.85 \mathrm{M}$, but at or near the intake of birds on the 1 vs. 1.5 M. If this is the case, however, then it indicates that the birds in treatment $0.5 \mathrm{vs} .1 \mathrm{M}$ regulated imperfectly, because their intakes fell between the rails for the two foods on offer, rather than on the $1 \mathrm{M}$ rail which lies closer to the presumed target. Either way, therefore, the birds in both experiments regulated their sugar intake tightly (aligned on the y axis), but those given a choice of two sugar solutions (Fig. 2) regulated the balance of sugar:water less precisely than those choosing between one sugar solution and supplementary water (Fig. 1). This might reflect the greater challenges to the sensory systems of distinguishing between alternatives that are more similar (two sucrose solutions) than those that are more different (one sucrose solution vs. supplementary water) (Schaefer et al. 2003). As a result, there could be a greater influence of 
side bias (Jackson et al. 1998) in the experiment involving paired sugar solutions: birds sometimes stubbornly feed from one side even if it is a less desirable sugar concentration, so that even after averaging over two periods with the feeders switched, intake will still fall between the two rails. It might also suggest that in the wild supplementary water plays a prominent role in the regulation of water status in sunbirds.

\section{Changes in nutrient demand: moving targets}

Intake targets are, of course, not static, but move with the changing nutrient needs associated with development (e.g. growth demands), and as changes in the environment demand different behavioural and physiological responses from the animal. We have shown in figures 1 and 2 that sunbirds defend a sugar:water intake target, and the question we now address is whether their regulation of food intake dynamically tracks changes in nutrient demand arising from behavioural and physiological responses to environmental conditions (Raubenheimer and Simpson 1997).

This question was addressed by comparing intakes of whitebellied sunbirds kept individually in standard bird cages (where they could see and hear each other) to intakes of individuals kept in white Perspex cages in isolation from each other (Köhler et al. 2010a; Köhler et al. 2008; Purchase et al. unpub data). The isolated birds moved less and sang less than those in standard cages, and also had a lower sugar intake over a range of sucrose concentrations than active birds in standard bird cages, although all other environmental constants were identical (One-way ANOVA: $F_{1,14}>22.23, P<0.001$; Fig. 3a). This suggests that the active birds compensated for the costs of movement by ingesting additional sucrose.

A similar shift of the sugar intake target is evident when the birds' metabolic requirements are altered by placing them in different air temperatures. Defending a constant body temperature is more energetically costly at lower air temperatures. In addition, energetic costs for warming the ingested nectar to body temperature increase with decreasing nectar temperature (Lotz et al. 2003). Consequently, whitebellied sunbirds ( $N=9$ ) increased their hourly sugar intake substantially when kept at $5^{\circ} \mathrm{C}$, compared to $25^{\circ} \mathrm{C}$ (RM-ANOVA: $F_{1,8}=21.73$, 
$P<0.01$; Fig. 3b) (Köhler et al. 2010b). Rats have also been shown to compensate in this way nutritionally for differences in environmental temperature (Simpson and Raubenheimer 1997).

\section{Compensation for perturbations to nutrient supply}

Data presented in the previous section show that whitebellied sunbirds regulate intake homeostatically to compensate for fluctuations in sugar demand. Do they also compensate for perturbations to nutrient supply? This question has been addressed by comparing afternoon intakes of captive birds subjected to an enforced $2 \mathrm{~h}$ midday fast with their intakes on a control day with uninterrupted feeding (Köhler et al. 2011; Nicolson et al. 2005). Fig. 4a shows that the birds compensated for the enforced disruption to food supply by increasing post-fast intakes compared with the control day, but the compensation was incomplete. Many animals compensate for such ingestive shortfalls by increasing the efficiency with which they utilise ingested nutrients (Raubenheimer and Simpson 1998). This is unlikely the case for sunbirds, however, since these birds assimilate $>99 \%$ of sucrose even when feeding at maximal rate (Köhler et al. 2010b). By contrast with sunbirds, similar experiments have shown that captive hummingbirds did increase consumption to compensate for an enforced $2 \mathrm{~h}$ midday fast, and consequently lost mass (Tooze and Gass 1985) suggesting that those birds lack the ability to compensate homeostatically for disruptions in feeding.

Evidence suggests, furthermore, that sunbirds show ingestive compensation not only when food supply is experimentally disrupted, but also for disruptions that arise from the natural diurnal pattern of activity. Köhler et al. (2008) measured hourly intakes through the feeding day of sunbirds given either a dilute $(0.31 \mathrm{M})$, a concentrated $(1.35 \mathrm{M})$ or a near-balanced $(0.63 \mathrm{M})$ sucrose solution. Fig. $4 \mathrm{~b}$ shows that on all three foods the pattern of intake across the day was unevenly spaced, with greater intake rates in the mornings compared with the afternoons. A likely explanation for the uneven spacing of intake is that the high rate of early feeding reflects compensation for the overnight fast (Fleming et al. 2004a). 


\section{Adding a third dimension: salt}

The preceding analyses all concern a low-dimensional nutritional system (sugar and water), which models a single food source for sunbirds (nectar). However, sunbirds complement their nectar intake with arthropods which provide the suite of other nutrients needed to meet their diverse nutritional demands. Recent experiments have explored the interactive effects of nectar (water and sugar) with one such nutrient, salt.

Fig. 1 shows that when feeding on very dilute nectar $(\leq 0.1 \mathrm{M}$ sucrose $)$, whitebellied sunbirds ingest up to five times their body mass in preformed water, but the resulting sugar intake is still not sufficient to maintain energy balance (Nicolson and Fleming 2003a). While these sugar concentrations are lower than the natural range of nectar concentrations reported for sunbirdpollinated flowers, heavy rain or high humidity may dilute nectar in unprotected flowers (Nicolson and Thornburg 2007). With the extremely high water fluxes on such dilute diets, excretion of electrolytes is higher than on moderate and concentrated nectar diets, suggesting that birds may be constrained by the progressive loss of solutes (Fleming and Nicolson 2003).

Purchase et al. (2010) tested this by establishing whether the addition of electrolytes $(\mathrm{NaCl})$ resulted in greater intakes of a dilute diet $(0.1 \mathrm{M}$ sucrose). Sugar intake indeed increased with increasing dietary $\mathrm{NaCl}$ concentration, and at the highest salt concentrations $(10$ and $20 \mathrm{mM}$ $\mathrm{NaCl}$ ) reached the sugar intake achieved on more concentrated sucrose solutions (Fig. 5). On diets containing salt, birds were able to consume a remarkable eight times their body mass in preformed water per day.

The increase in sugar intake with increased $\mathrm{NaCl}$ in the diet suggests that sunbirds are limited in their consumption of extremely dilute diets by losses of $\mathrm{Na}^{+}$. Sodium ions aid glucose transport across membranes against a concentration gradient. The sodium-linked glucose transporter SLGT-1, located in the apical membrane of intestinal enterocytes, transports one glucose molecule along with two $\mathrm{Na}^{+}$ions from the intestinal lumen to the cytosol (Scheepers et al. 2004). As the extent of paracellular glucose absorption in sunbirds decreases with increasing nectar dilution (Napier et al. 2008), this mediated glucose uptake may become more important on 
dilute diets. It would be interesting to establish whether sunbirds select higher dietary intakes of electrolytes when feeding on dilute nectars, as do gorillas to supplement the low sodium concentrations of foliage (Rothman et al. 2006).

\section{Concluding remarks}

The Geometric Framework provides a powerful tool to address questions about nutrient regulation in birds occupying the special nutritional niche of nectar consumption. Not surprisingly, whitebellied sunbirds regulate sugar intake tightly, and prioritise sugar over water intake regulation. On extremely dilute nectar diets, sodium enables the birds to increase food intake and maintain energy balance. The prioritisation of sugar intake over water intake is characteristic of specialist nectar-feeding birds. Sunbirds, hummingbirds and honeyeaters defend a constant energy intake over a wide range of nectar concentrations in both choice and no-choice experiments (Fleming et al. 2008; López-Calleja et al. 1997; Lotz and Nicolson 1999; for a review see Martínez del Rio et al. 2001). The adjustment of sugar intake according to metabolic requirements has also been shown for different species, including amethyst sunbirds Chalcomitra amethystina (Köhler et al. 2010b), broadtailed hummingbirds Selasphorus platycercus (Fleming et al. 2004b) and brown honeyeaters Lichmera indistincta (Köhler 2009). The importance of dietary salt when birds are fed very dilute diets similarly applies to New Holland honeyeaters Phylidonyris novaehollandiae (Purchase et al. 2010). We are therefore confident that the nutrient regulation demonstrated in whitebellied sunbirds using the Geometric Framework applies to avian nectarivores in general, but it remains to be determined how the geometric parameters of nutritional regulation differ with phylogenetic and ecological differences among these nectarivores. Such differences might be subtle, but functionally important. Among folivorous insects, for example, there is a consistent difference in rules of compromise between specialist and generalist feeders, where generalists over-eat a macronutrient to a greater extent than specialists to gain limiting nutrients in the diet (Lee et al. 2006; Lee et al. 2004; Raubenheimer and Jones 2006; Raubenheimer and Simpson 2003).

Most animals obtain dietary water both as a component of food and separately through drinking. Only one previous study has considered water as a nutrient in the context of GF 
analysis. Raubenheimer and Gäde (1994) offered locusts a meal of dry food (lyophilized grass) before or after a drink of water, and found that both treatments led to higher water intakes and lower food intakes than in locusts given fresh grass. When Dussutour and Simpson (2008) examined carbohydrate regulation in experimental ant colonies fed sucrose solutions of different concentration, their focus was not on water as a nutrient, but on carbohydrate regulation in the face of diet dilution. Nectar-feeding birds must make foraging decisions among a wide range of nectar concentrations, many of which impose very high water loads (Johnson and Nicolson 2008). On the other hand, water drinking in the wild may be necessary to dilute concentrated nectars (Fisher 1972).

While nectar contains salts, proteins and amino acids in addition to the dominant ingredients of sugar and water (Nicolson and Thornburg 2007), arthropod feeding probably contributes the bulk of the other nutrients required by nectar-feeding birds, especially their protein needs (Markman et al. 2004). Future research should examine whether nectar-feeding birds regulate their protein intake as strongly as that of sugars, and whether protein is regulated independently of sugar and water. Without the inclusion of protein in their diet, captive sunbirds lose body mass rapidly (Nicolson and Fleming 2003a). The intake of amino acids by sunbirds is highly variable between individuals in short-term studies (Leseigneur et al. 2007), and longer test periods are needed to reveal the protein intake target. We have shown that salt is important in maintaining energy balance on very dilute diets, but also need to examine salt intake targets on more normal nectar concentrations. Lastly, plant secondary metabolites associated with herbivore defence, which are found in the nectar of many plants (Adler 2000), may influence the dietary choices of nectar-feeding birds.

\section{Acknowledgements}

This work was supported by the University of Pretoria, the South African National Research Foundation and the Claude Leon Foundation. DR received support from the Massey University Research Fund. 


\section{References}

Adler LS (2000) The ecological significance of toxic nectar. Oikos 91:409-420

Altaye SZ, Pirk CWW, Crewe RM, Nicolson SW (2010) Convergence of carbohydrate-biased intake targets in caged worker honeybees fed different protein sources. J Exp Biol 213:3311-3318

Baker HG, Baker I, Hodges SA (1998) Sugar composition of nectars and fruits consumed by birds and bats in the tropics and subtropics. Biotropica 30:559-586

Barnes K, Nicolson SW, van Wyk B-E (1995) Nectar sugar composition in Erica. Biochem Syst Ecol 23:419-423

Behmer ST, Joern A (2008) Coexisting generalist herbivores occupy unique nutritional feeding niches. PNAS 105:1977-1982

Dussutour A, Latty T, Beekman M, Simpson SJ (2010) Amoeboid organism solves complex nutritional challenges. PNAS 107:4607-4611

Dussutour A, Simpson SJ (2008) Carbohydrate regulation in relation to colony growth in ants. J Exp Biol 211:2224-2232

Dussutour A, Simpson SJ (2009) Communal nutrition in ants. Curr Biol 19:740-744

Felton AM, Felton A, Raubenheimer D, Simpson SJ, Foley WJ, Wood JT, Wallis IR, Lindenmayer DB (2009) Protein content of diets dictates the daily energy intake of a free-ranging primate. Behav Ecol 20:685-690

Fisher CD (1972) Drinking patterns and behavior of Australian desert birds in relation to their ecology and abundance. Condor 74:111-136

Fleming PA, Gray DA, Nicolson SW (2004a) Circadian rhythm of water balance and aldosterone excretion in the whitebellied sunbird Nectarinia talatala. J Comp Physiol B 174:341-346

Fleming PA, Hartmann Bakken B, Lotz CN, Nicolson SW (2004b) Concentration and temperature effects on sugar intake and preferences in a sunbird and a hummingbird. Funct Ecol 18:223-232

Fleming PA, Nicolson SW (2003) Osmoregulation in an avian nectarivore, the whitebellied sunbird Nectarinia talatala: response to extremes of diet concentration. J Exp Biol 206:1845-1854 
Fleming PA, Xie S, Napier KR, McWhorter TJ, Nicolson SW (2008) Nectar concentration affects sugar preferences in two Australian honeyeaters and a lorikeet. Funct Ecol 22:599-605

Gosby AK, Conigrave AD, Lau NS, Iglesias MA, Hall RM, Jebb SA, Brand-Miller J, Caterson ID, Raubenheimer D, Simpson SJ (2011) Testing protein leverage in lean humans: a randomised controlled experimental study. PLoS ONE, in press

Jackson S, Nicolson SW, Lotz CN (1998) Sugar preferences and "side bias" in Cape sugarbirds and lesser double-collared sunbirds. Auk 115:156-165

Johnson SD, Nicolson SW (2008) Evolutionary associations between nectar properties and specificity in bird pollination systems. Biol Lett 4:49-52

Köhler A (2009) Food quality, fasting periods and temperature stress: effects of energy challenges on the feeding patterns of avian nectarivores. University of Pretoria, $\mathrm{PhD}$ thesis, Pretoria, South Africa

Köhler A, Leseigneur CDC, Verburgt L, Nicolson SW (2010a) Dilute bird nectars: viscosity constrains food intake by licking in a sunbird. Am J Physiol 299:R1068-R1074

Köhler A, Verburgt L, Fleming PA, McWhorter TJ, Nicolson SW (2011) Interruptions in nectar availability: responses of White-bellied Sunbirds (Cinnyris talatala) and Brown Honeyeaters (Lichmera indistincta). Emu 111:252-258

Köhler A, Verburgt L, McWhorter TJ, Nicolson SW (2010b) Energy management on a nectar diet: can sunbirds meet the challenges of low temperature and dilute food? Funct Ecol 24:1241-1251

Köhler A, Verburgt L, Nicolson SW (2008) Nectar intake of whitebellied sunbirds (Cinnyris talatala): Can meal size be inferred from feeding duration? Physiol Biochem Zool $81: 682-687$

Lee KP, Behmer ST, Simpson SJ (2006) Nutrient regulation in relation to diet breadth: A comparison of Heliothis sister species and a hybrid. J Exp Biol 209:2076-2084

Lee KP, Simpson SJ, Clissold FJ, Brooks R, Ballard JWO, Taylor PW, Soran N, Raubenheimer D (2008) Lifespan and reproduction in Drosophila: new insights from nutritional geometry. PNAS 105:2498-2503 
Lee KP, Simpson SJ, Raubenheimer D (2004) A comparison of nutrient regulation between solitarious and gregarious phases of the specialist caterpillar, Spodoptera exempta (Walker). J Insect Physiol 50:1171-1180

Leseigneur CDC, Nicolson SW (2009) Nectar concentration preferences and sugar intake in the white-bellied sunbird, Cinnyris talatala (Nectariniidae). J Comp Physiol B 179:673-679

Leseigneur CDC, Verburgt L, Nicolson SW (2007) Whitebellied sunbirds (Nectarinia talatala, Nectariniidae) do not prefer artificial nectar containing amino acids. J Comp Physiol B 177:679-685

López-Calleja MV, Bozinovic F, Martínez del Rio C (1997) Effects of sugar concentration on hummingbird feeding and energy use. Comp Biochem Physiol A 118:1291-1299

Lotz CN, Martínez del Rio C, Nicolson SW (2003) Hummingbirds pay a high cost for a warm drink. J Comp Physiol B 173:455-462

Lotz CN, Nicolson SW (1999) Energy and water balance in the lesser double-collared sunbird (Nectarinia chalybea) feeding on different nectar concentrations. J Comp Physiol B 169:200-206

Markman S, Pinshow B, Wright J, Kotler BP (2004) Food patch use by parent birds: to gather food for themselves or for their chicks? J Anim Ecol 73:747-755

Martínez del Rio C, Schondube JE, McWhorter TJ, Herrera LG (2001) Intake responses in nectar feeding birds: digestive and metabolic causes, osmoregulatory consequences, and coevolutionary effects. Am Zool 41:902-915

Mayntz D, Raubenheimer D, Salomon M, Toft S, Simpson SJ (2005) Nutrient-specific foraging in invertebrate predators. Science 307:111-113

Napier KR, Purchase C, McWhorter TJ, Nicolson SW, Fleming PA (2008) The sweet life: diet sugar concentration influences paracellular glucose absorption. Biol Lett 4:530-533

Nicolson SW, Fleming PA (2003a) Energy balance in the Whitebellied Sunbird Nectarinia talatala: constraints on compensatory feeding, and consumption of supplementary water. Funct Ecol 17:3-9

Nicolson SW, Fleming PA (2003b) Nectar as food for birds: the physiological consequences of drinking dilute sugar solutions. Plant Syst Evol 238:139-153 
Nicolson SW, Hoffmann D, Fleming PA (2005) Short-term energy regulation in nectar-feeding birds: the response of Whitebellied Sunbirds (Nectarinia talatala) to a midday fast. Funct Ecol 19:988-994

Nicolson SW, Thornburg RW (2007) Nectar chemistry. In: Nicolson SW, Nepi M, Pacini E (eds) Nectaries and nectar. Springer, Dordrecht, Netherlands, pp 215-264

Purchase C, Nicolson SW, Fleming PA (2010) Added salt helps sunbirds and honeyeaters maintain energy balance on extremely dilute nectar diets. J Comp Physiol B 180:12271234

Raubenheimer D (2011) Towards a quantitative nutritional ecology: the right-angled mixture triangle. Ecol Monogr 81:407-427

Raubenheimer D, Gäde G (1994) Hunger-thirst interactions in the Locust, Locusta migratoria. J Insect Physiol 40:631-639

Raubenheimer D, Jones SA (2006) Nutritional imbalance in an extreme generalist omnivore: tolerance and recovery through complementary food selection. Anim Behav 71:12531262

Raubenheimer D, Mayntz D, Simpson SJ, Tøft S (2007) Nutrient-specific compensation following diapause in a predator: implications for intraguild predation. Ecology 88:25982608

Raubenheimer D, Simpson SJ (1993) The geometry of compensatory feeding in the locust. Anim Behav 45:953 - 964

Raubenheimer D, Simpson SJ (1997) Integrative models of nutrient balancing: application to insects and vertebrates. Nutr Res Rev 10:151-179

Raubenheimer D, Simpson SJ (1998) Nutrient transfer functions: the site of integration between feeding behaviour and nutritional physiology. Chemoecol 8:61-68

Raubenheimer D, Simpson SJ (1999) Integrating nutrition: a geometrical approach. Entomol Exp Appl 91:67-82

Raubenheimer D, Simpson SJ (2003) Nutrient balancing in grasshoppers: behavioural and physiological correlates of dietary breadth. J Exp Biol 206:1669-1681

Raubenheimer D, Simpson SJ (2006) The challenge of supplementary feeding: can geometric analysis help save the kakapo? Notornis 53:100-111 
Raubenheimer D, Zemke-White WL, Phillips RJ, Clements KD (2005) Algal macronutrients and food selection by the omnivorous marine fish Girella tricuspidata. Ecology 86:26012610

Rothman JM, Raubenheimer D, Chapman CA (2011) Nutritional geometry: gorillas prioritize non-protein energy while consuming surplus protein. Biol Lett, doi $10.1098 / \mathrm{rsbl} .2011 .0321$

Rothman JM, Van Soest PJ, Pell AN (2006) Decaying wood is a sodium source for mountain gorillas. Biol Lett 2:321-324

Schaefer HM, Schmidt V, Bairlein F (2003) Discrimination abilities for nutrients: which difference matters for choosy birds and why? Anim Behav 65:531-541

Scheepers A, Joost HG, Schurmann A (2004) The glucose transporter families SGLT and GLUT: molecular basis of normal and aberrant function. JPEN-Parenter Enter 28:365372

Shariatmadari F, Forbes JM (1993) Growth and food intake responses to diets of different protein contents and a choice between diets containing two concentrations of protein in broiler and layer strains of chicken. Brit Poultry Sci 34:959-970

Simpson SJ, Batley R, Raubenheimer D (2003) Geometric analysis of macronutrient intake in humans: the power of protein? Appetite 41:123-140

Simpson SJ, Raubenheimer D (1993) A multi-level analysis of feeding behaviour: the geometry of nutritional decisions. Philos T Roy Soc B 342:381-402

Simpson SJ, Raubenheimer D (1995) The geometric analysis of feeding and nutrition: a user's guide. J Insect Physiol 41:545-553

Simpson SJ, Raubenheimer D (1997) Geometric analysis of macronutrient selection in the rat. Appetite 28:201-213

Simpson SJ, Raubenheimer D (2005) Obesity: the protein leverage hypothesis. Obes Rev 6:133142

Simpson SJ, Sibly RM, Lee KP, Behmer ST, Raubenheimer D (2004) Optimal foraging when regulating intake of multiple nutrients. Anim Behav 68:1299-1311

Tooze ZJ, Gass CL (1985) Responses of rufous hummingbirds to midday fasts. Can J Zool 63:2249-2253 
Welch KC, Suarez RK (2007) Oxidation rate and turnover of ingested sugar in hovering Anna's (Calypte anna) and rufous (Selasphorus rufus) hummingbirds. J Exp Biol 210:2154-2162 


\section{Figure legends}

Figure 1. Daily sucrose and water intake of seven whitebellied sunbirds (mean $\pm \mathrm{SE}$ ) fed a wide range of sucrose concentrations $(0.07-2.5 \mathrm{M})$ for one day (Nicolson and Fleming 2003a). Supplementary water was provided and intake of supplementary water was added to the intake of preformed water.

Figure 2. Sucrose and water intake of ten whitebellied sunbirds $\left(\mathrm{g} \mathrm{h}^{-1}\right.$, mean $\left.\pm \mathrm{SE}\right)$ during paired preference tests (Leseigneur and Nicolson 2009). Birds were offered paired sucrose solutions ranging from 0.25 to $2.5 \mathrm{M}$.

Figure 3. Sucrose and water intake $\left(\mathrm{g} \mathrm{h}^{-1}\right)$ of whitebellied sunbirds fed three different sucrose concentrations under two activity and temperature regimes (mean $\pm \mathrm{SE}$ ). (A) Birds of the first group were kept individually in standard bird cages, where they could see and hear each other (active birds, black symbols), birds of the second group were kept in white Perspex cages in isolation from each other (inactive birds, white symbols) ( $\mathrm{N}=16$, data from Köhler et al. (2008, 2010a) and Purchase et al. (unpub data). (B) Birds were kept once at $25^{\circ} \mathrm{C}$ (warm, white symbols) and once at $5^{\circ} \mathrm{C}$ (cold, black symbols) ( $\mathrm{N}=9$, data from Köhler et al. (2010b).

Figure 4. Cumulative sucrose and water intake following interruptions in feeding of sunbirds. (A) Compensation for disrupted food supply by whitebellied sunbirds $(\mathrm{N}=8$, mean, error bars omitted for clarity, data from Köhler et al. (2011)). Cumulative intakes between $07 \mathrm{~h} 00$ and $19 \mathrm{~h} 00$ of sunbirds on days of ad libitum feeding (solid symbols) and on days when they were subjected to an enforced $2 \mathrm{~h}$ fast from $10 \mathrm{~h} 00$ to $12 \mathrm{~h} 00$ (open symbols). Squares closest to the origin show the cumulative intakes at $12 \mathrm{~h} 00$ (i.e. immediately after the fast) of the birds on $a d$ libitum and manipulated days, with the distance between these points (the length of line f) showing the effect of the fast on cumulative intakes to $12 \mathrm{~h} 00$. The squares furthest from the origin show the cumulative intakes of the two groups by $19 \mathrm{~h} 00$. The dashed vertical and horizontal lines show the expected intake of experimental birds if they did not compensate for the enforced fast (i.e. if the length of line $\mathrm{f}$ was maintained throughout the day). However, the actual difference in cumulative intakes between control and fasted days (line d) was smaller than 
$\mathrm{f}$ by the length of line $\mathrm{c}$, this giving the extent to which the sunbirds compensated for the enforced midday fast. The circles give cumulative intakes on control and fasted days at the ends of successive meals between $12 \mathrm{~h} 00$ and 19h00. (B) Cumulative sucrose and water intake (g) of whitebellied sunbirds fed three different sucrose concentrations for $11 \mathrm{~h}(\mathrm{~N}=10$, mean $\pm \mathrm{SE}$, data from Köhler et al. (2008).

Figure 5. Daily sucrose and water intake of eight whitebellied sunbirds (mean $\pm \mathrm{SE}$ ) on $0.1 \mathrm{M}$ sucrose diets with added $\mathrm{NaCl}(0-20 \mathrm{mM})$ (Purchase et al. 2010). For comparative purposes, the sucrose intake of whitebellied sunbirds (mean $\pm \mathrm{SE}$ ) on more concentrated diets $(0.25-2.5$ M) is indicated by the dashed lines. 


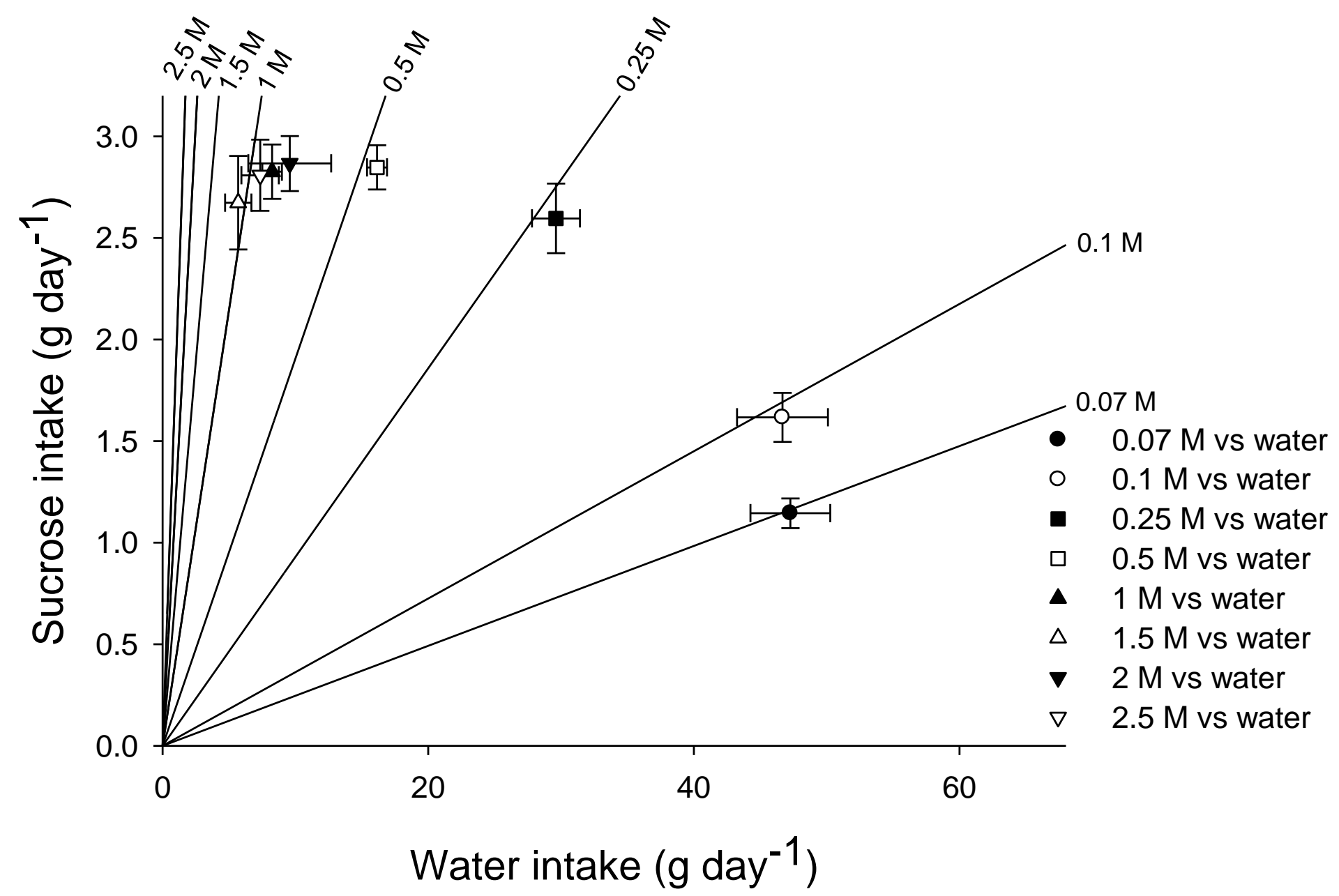

Figure 1. 


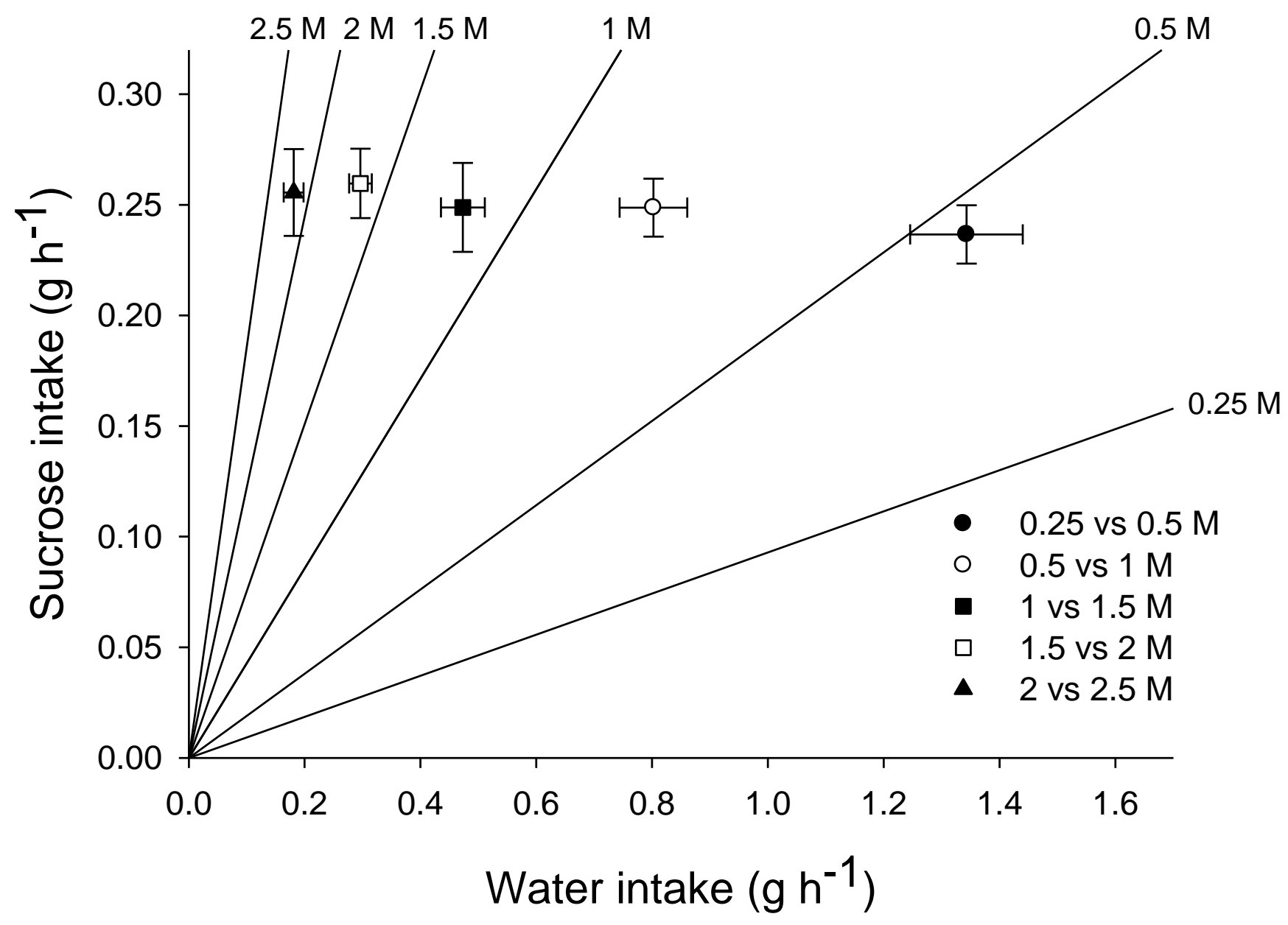

Figure 2. 


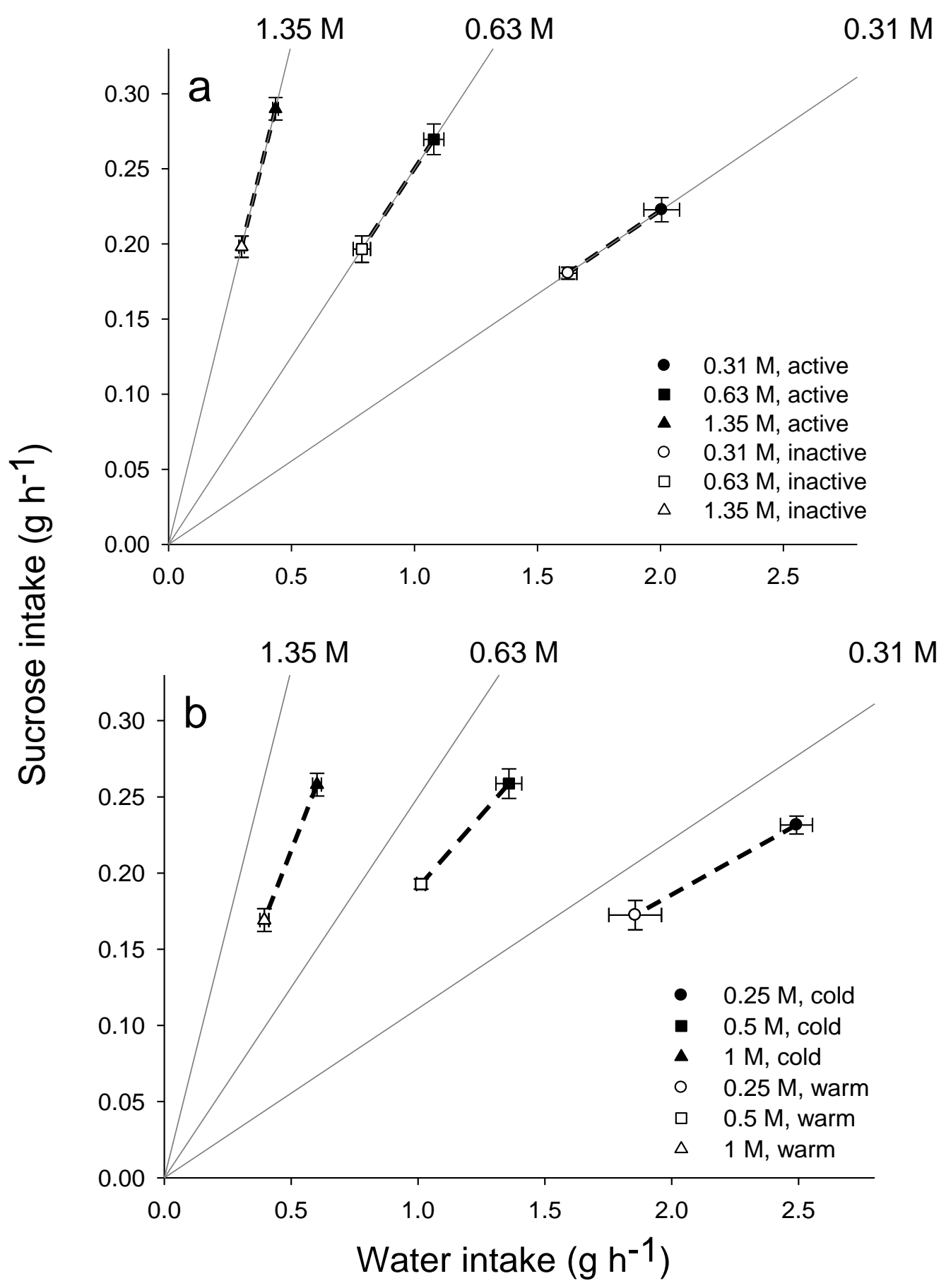




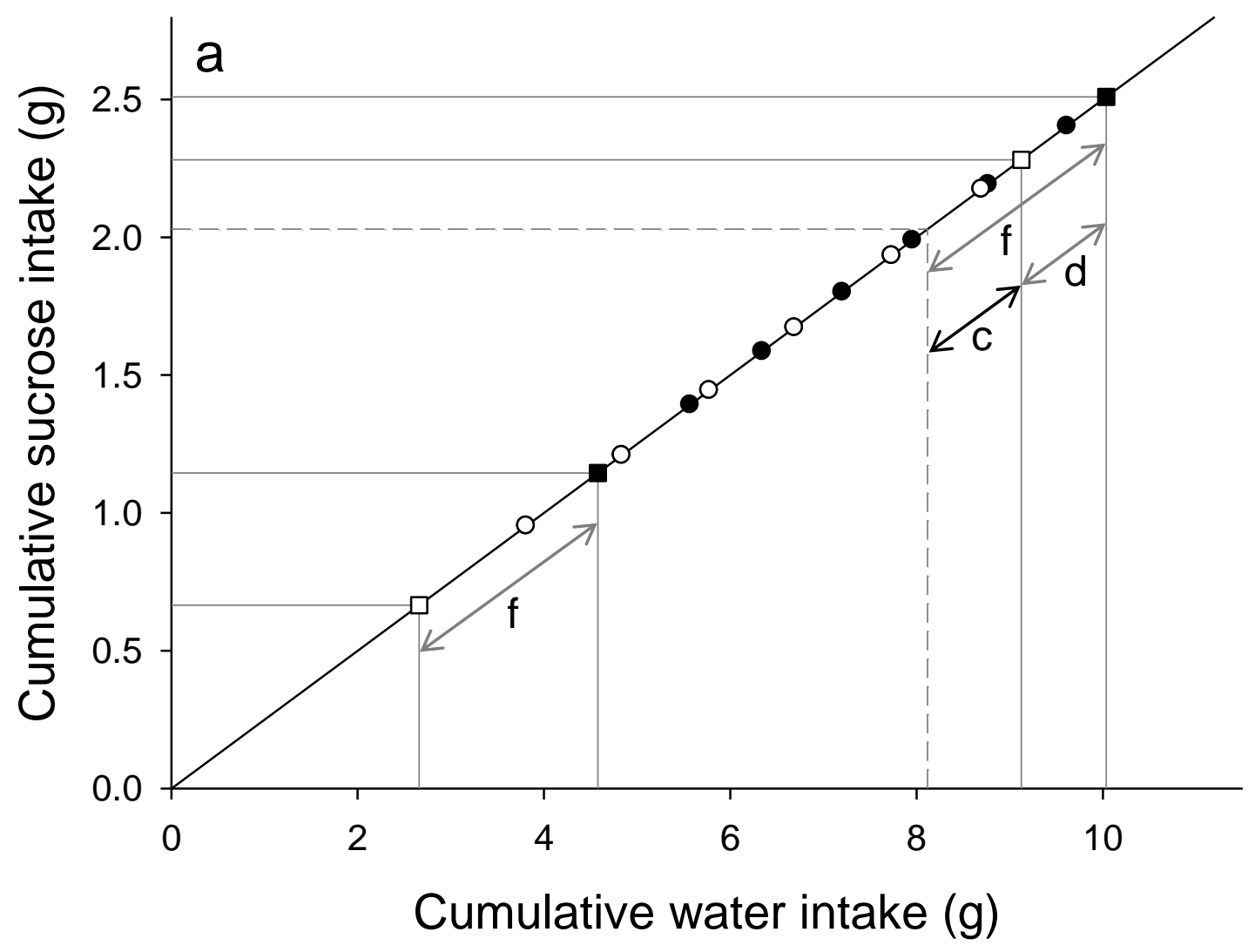

Figure 4a. 


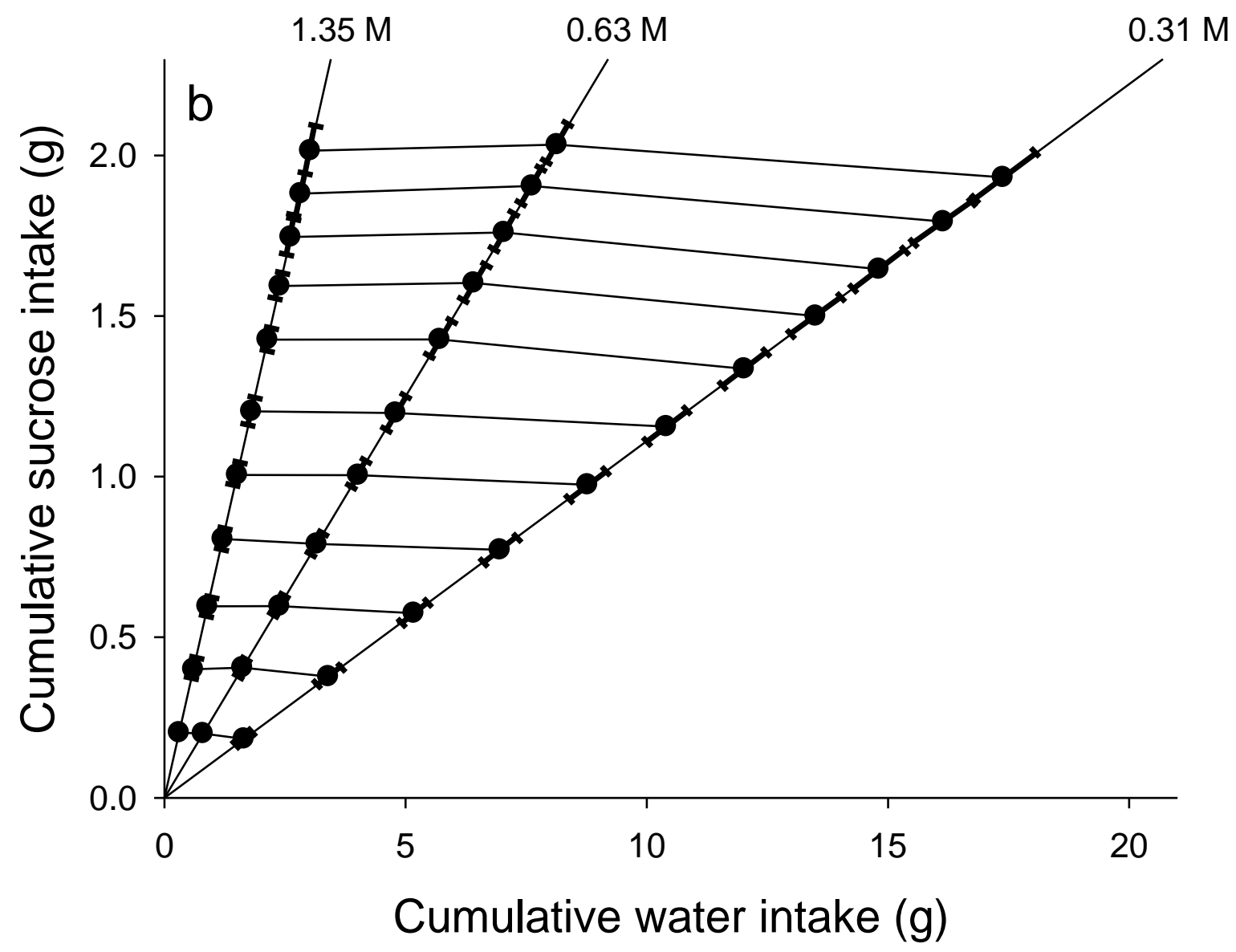

Figure 4b. 


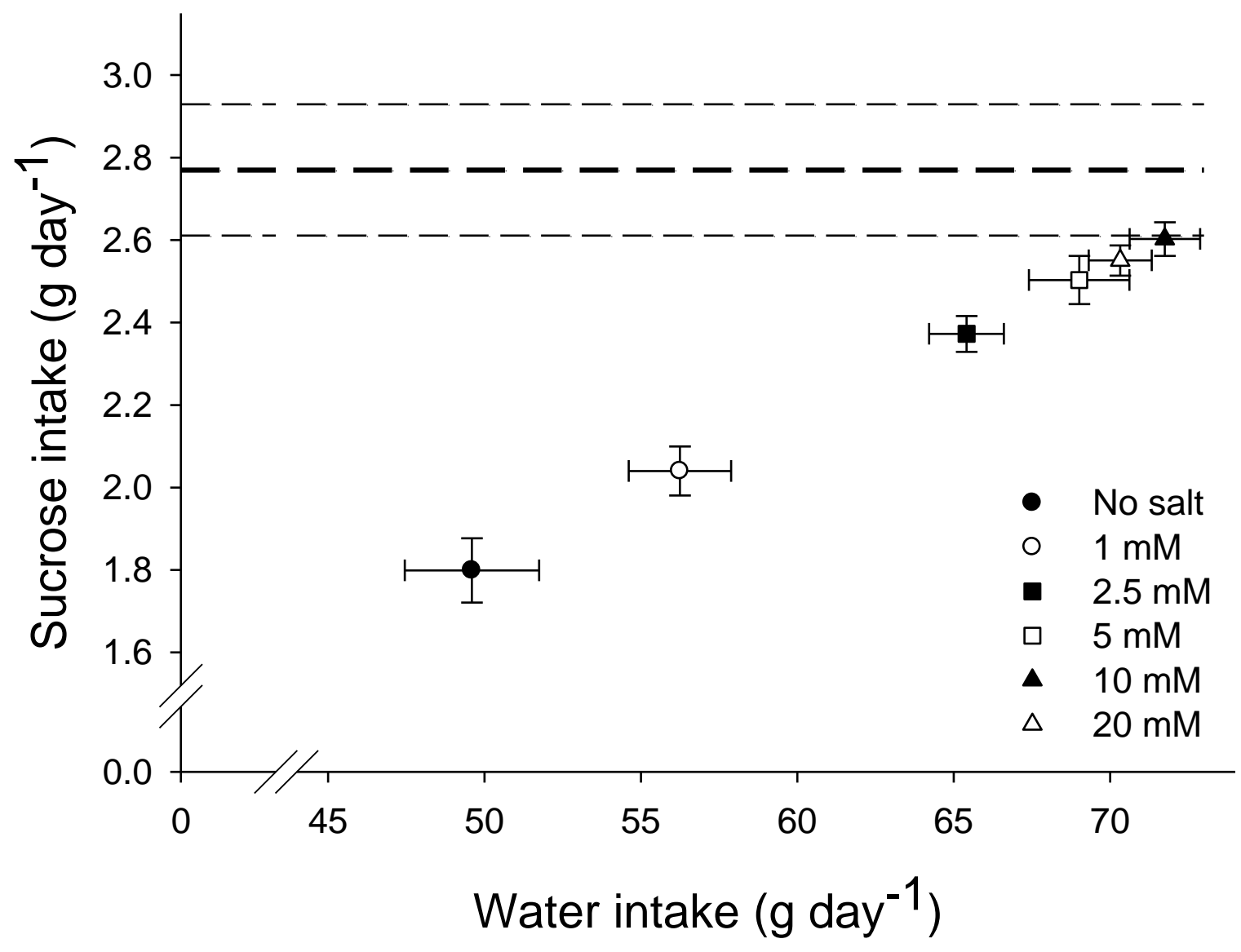

Figure 5. 